\title{
Economic evaluation of the MEDENOX trial: A Canadian perspective
}

\author{
André Lamy MD FRCSC MHSc ${ }^{1}$, Xiaoyin Wang MA MSc ${ }^{2}$, \\ Rosanne Kent RN BA MSc ${ }^{3}$, Kelly M Smith MSc ${ }^{3}$, Amiram Gafni DSc ${ }^{4}$
}

\begin{abstract}
A Lamy, X Wang, R Kent, KM Smith, A Gafni. Economic evaluation of the MEDENOX trial: A Canadian perspective. Can Respir J 2002;9(3):169-177.
\end{abstract}

OBJECTIVE: To perform an economic evaluation of the Prophylaxis in Medical Patients with Enoxaparin (MEDENOX) trial from a Canadian perspective.

METHOD: Using a decision tree model, cost effectiveness analysis was carried out to compare the costs and consequences of thromboprophylaxis using enoxaparin $40 \mathrm{mg}$ with placebo in tertiary and community settings. From a third party payer's perspective, the model calculated the expected rate of symptomatic venous thromboembolism (VTE), and the total expected cost of prophylaxis and VTE management, including inpatient and outpatient treatment, professional fees and long term therapy. Data were derived directly from the MEDENOX trial. Costs are direct medical costs in year 2000 Canadian dollars.

RESULTS: In a tertiary setting in which the estimated inpatient to outpatient deep vein thrombosis treatment ratio was $10 \%: 90 \%$, the total expected cost per patient was $\$ 64$ in the enoxaparin group and $\$ 62$ in the placebo group. The expected symptomatic VTE rates were $0.8 \%$ and $3.1 \%$ in the enoxaparin and placebo groups, respectively. The incremental cost effectiveness of enoxaparin $40 \mathrm{mg}$ versus placebo was \$87/VTE avoided. In a community hospital setting (with a 50\%:50\% inpatient to outpatient deep vein thrombosis treatment ratio), the total expected cost per patient was $\$ 68$ in the enoxaparin group compared with $\$ 72$ in the placebo group, indicating that prophylaxis with enoxaparin $40 \mathrm{mg}$ was cost sav- ing. The model was sensitive to the inpatient to outpatient ratio. However, within each setting, the results were not sensitive to changes in key variables.

CONCLUSION: For patients hospitalized for acute respiratory failure, congestive heart failure or acute infectious disease and who are at moderate risk of developing VTE, thromboprophylaxis with enoxaparin $40 \mathrm{mg}$ daily is a cost effective strategy in both tertiary and community settings.

Key Words: Cost effectiveness; Enoxaparin; Heart failure; Infection; Medical patients; Respiratory disease; Venous thromboembolism; Venous thromboprophylaxis

\section{L'évaluation économique de l'essai MEDENOX : Une perspective canadienne}

\begin{abstract}
OBJECTIF : Procéder à l'évaluation économique de l'essai sur la prophylaxie à l'énoxaparine des patients (MEDENOX), selon une perspective canadienne.

MÉTHODOLOGIE : Au moyen d'un modèle décisionnel arborescent, une analyse coût-efficacité a été effectuée pour comparer les coûts et les conséquences d'une thromboprophylaxie au moyen de $40 \mathrm{mg}$ d'énoxaparine par rapport à un placebo dans des établissements de soins généraux et de soins tertiaires. Du point de vue du tiers payeur, le modèle comparait le taux prévu de thromboembolie veineuse (TV) symptomatique au coût total prévu de la prophylaxie symptomatique et de la prise en charge de la TV, y compris le traitement en milieu hospitalier et ambulatoire, les honoraires professionnels et le traitement à long terme. Les données ont
\end{abstract}

${ }^{1}$ CADENCE Research Group and Faculty of Health Sciences, McMaster University; ${ }^{2}$ CADENCE Research Group, Hamilton Health Sciences General Site; ${ }^{3} \mathrm{CADENCE}$ Research Group and McMaster University; ${ }^{4}$ Faculty of Health Sciences, McMaster University, Hamilton, Ontario Correspondence and reprints: Dr A Lamy, 2-E Wing, CADENCE Research Group, Hamilton Health Sciences - General Site,

237 Barton Street East, Hamilton, Ontario L8L 2X2. Telephone 905-527-4322 ext 44462, fax 905-577-1452, e-mail lamyand@hhsc.ca 
été dérivées directement de l'essai MEDENOX. Les coûts, des frais médicaux directs, sont en dollars canadiens pour l'an 2000.

RÉSULTATS : Dans un établissement de soins tertiaires, où le traitement d'une thrombose veineuse profonde dans la population hospitalisée et ambulatoire affiche un ratio de $10 \%: 90 \%$, le coût total prévisible par patient était de $64 \$$ au sein du groupe traité à l'énoxaparine par rapport à $62 \$$ au sein de celui traité à l'aide d'un placebo. Le taux de TV symptomatique prévisible s'établissait à 0,8 \% et à $3,1 \%$ dans les groupes traités à l'énoxaparine et par un placebo, respectivement. La rentabilité incrémentielle de $40 \mathrm{mg}$ d'énoxaparine par rapport au placebo s'élevait à 87 \$ par TV évitée. Dans un établissement de soins généraux, (où le traitement d'une thrombose veineuse profonde dans la population hospitalisée et ambulatoire affiche un ratio de $50 \%: 50 \%$ ), le coût total prévisible par patient correspondait à $68 \$$ dans le groupe traité à l'énoxaparine par rapport à $72 \$$ dans celui traité au placebo, ce qui indique que la prophylaxie au moyen de $40 \mathrm{mg}$ d'énoxaparine est plus économique. Le modèle était sensible au ratio entre les patients hospitalisés et ambulatoires. Cependant, au sein de chaque établissement, les résultats n'étaient pas sensibles aux modifications des principales variables utilisées.

CONCLUSION : Chez les patients hospitalisés par suite d'une insuffisance respiratoire aiguë, d'une insuffisance cardiaque congestive ou d'une maladie infectieuse aiguë qui présentent un risque modéré de développer une TV, la thromboprophylaxie au moyen de $40 \mathrm{mg}$ d'énoxaparine par jour constitue une stratégie rentable, tant dans les établissements de soins généraux que de soins tertiaires.
$\mathrm{T}$ he safety, efficacy and cost effectiveness of thromboprophylaxis with low molecular weight heparin (LMWH) in patients undergoing surgery have been extensively documented, and LMWH prophylaxis in surgical populations is now universally recommended (1-10). In contrast to surgical patients, thromboprophylaxis has been less well studied in medical patients (acutely ill patients requiring hospitalization), and LMWH prophylaxis in medical patients remains underused (11-13), despite the fact that venous thromboembolism (VTE) is at least as common among medical patients as among surgical patients, and fatal pulmonary embolism (PE) is reported to occur more commonly in medical patients than in surgical patients (14-15).

In the recently published Prophylaxis in Medical Patients with Enoxaparin (MEDENOX) trial (16), enoxaparin (20 $\mathrm{mg}$ and $40 \mathrm{mg}$ once daily) was compared with placebo in 1102 medical patients who were at moderate risk of VTE. The MEDENOX study demonstrated a $63 \%$ reduction in VTE incidence when enoxaparin $40 \mathrm{mg}$ was compared with placebo. A recent American College of Chest Physicians consensus conference on antithrombotic therapy recommended LMWH prophylaxis for medical patients with a moderate risk of VTE (17).

The clinical findings of the MEDENOX trial, along with the American College of Chest Physicians recommendations, have the potential to affect substantially clinical practice concerning VTE prophylaxis in medical patients. Despite concerns regarding the cost of thromboprophylaxis in medical patients, little is known about the cost effectiveness of such a strategy. Two recent economic studies compared LMWH prophylaxis with no prophylaxis in the context of the MEDENOX trial (18-19), and all were in favour of using enoxaparin. However, these studies were performed within the context of the French and British health care systems. The aim of the present study was to conduct a cost effectiveness analysis of the MEDENOX trial from the perspective of the Canadian health care system.

\section{PATIENTS AND METHODS}

The MEDENOX trial was an international, multicentre, double-blind, placebo controlled, randomized trial in which 1102 patients older than 40 years were randomly assigned to receive a daily injection of $20 \mathrm{mg}$ enoxaparin, $40 \mathrm{mg}$ enoxaparin or placebo subcutaneously for $10( \pm 4)$ days to prevent VTE. To be eligible, patients had to be hospitalized for an acute illness such as acute respiratory failure or congestive heart failure. Patients with acute infectious diseases and other acute diseases had to have at least one additional risk factor for VTE to be included in the study. The baseline characteristics of patients were similar across the three study groups; on average, $53.5 \%$ of patients had acute respiratory failure, $53.1 \%$ had an acute infectious disease, and 24.9\% and 9.3\% had New York Heart Association class III and IV congestive heart failure, respectively.

The primary outcome was venous thrombosis between days 1 and 14, defined as deep vein thrombosis (DVT) detected by bilateral venography or duplex ultrasonography between days 6 and 14, or documented PE. The primary outcome was further stratified into seven subgroups: DVT alone, PE alone, PE and DVT, proximal DVT, distal DVT, symptomatic DVT and death from PE. The secondary outcome was the VTE rate between days 1 and 110.

Eight hundred sixty-six patients were included in the assessment of primary outcome; the reasons for exclusion were published elsewhere (16). The incidences of VTE were $5.5 \%$ (16 of 291) in patients receiving enoxaparin $40 \mathrm{mg}, 15 \%$ (43 of 287) in patients receiving enoxaparin $20 \mathrm{mg}$ and $14.9 \%$ (43 of 288) in patients receiving placebo. The benefit of risk reduction was maintained at three months. The incidence of major bleeding was not significantly different between the placebo group $(1.1 \%)$ and either of the enoxaparin groups $(1.7 \%$ in the $40 \mathrm{mg}$ group and $0.3 \%$ in the $20 \mathrm{mg}$ group). There were no differences in the death rates among the three groups.

\section{ECONOMIC MODEL OVERVIEW}

\section{The model design and expert panel}

A decision analytical model was developed to compare two alternative strategies - thromboprophylaxis using enoxaparin $40 \mathrm{mg}$ with no prophylaxis (placebo) - in terms of the total expected cost and the expected VTE rate. Total expected costs included the costs of the prophylactic drug and VTE treatment. The total expected outcome was quantified by the symptomatic VTE rate. For each strategy, the expected cost and outcome were estimated as a probabilityweighted sum of costs and outcomes that occurred during 


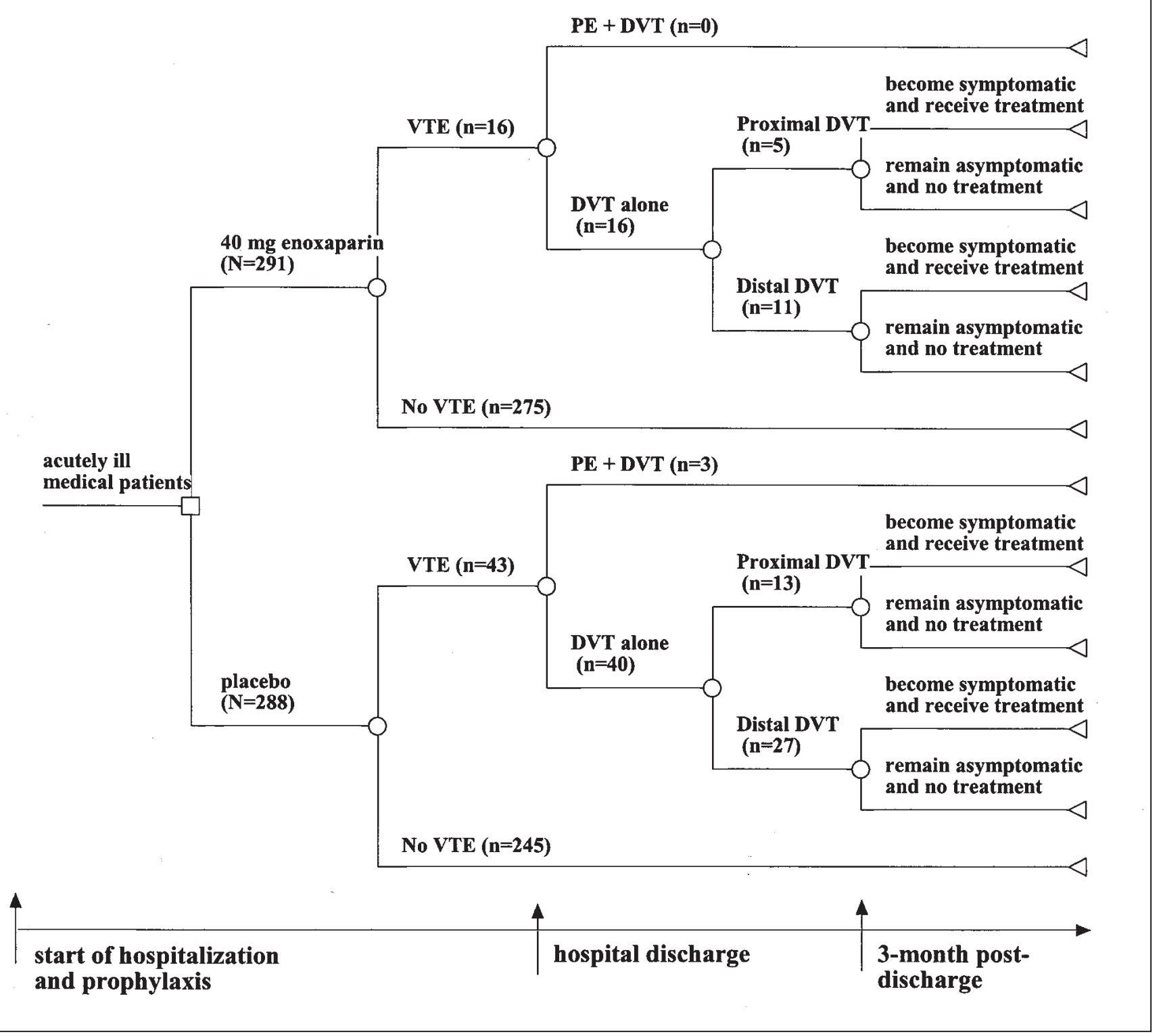

Figure 1) Decision tree model for patients in the Prophylaxis in Medical Patients with Enoxaparin (MEDENOX) trial. DVT Deep vein thrombosis; PE Pulmonary embolism; VTE Venous thromboembolism

hospitalization and over the three months of follow-up. The enoxaparin $20 \mathrm{mg}$ group was excluded from the model, because it did not demonstrate any significant VTE risk reduction in the MEDENOX trial.

In developing the model, a panel of experts was consulted, and consensus was reached with respect to the model assumptions, estimations of the probability of the symptomatic VTE rate for the follow-up period and health care resource use. An expert panel was necessary for three reasons. First, no health care resource data were collected in the MEDENOX trial. Second, most events reported as the MEDENOX primary outcome were asymptomatic and treated. However, it would be incorrect to calculate the total cost based on the asymptomatic rate, because in clinical practice, asymptomatic VTEs would not be treated and would incur no health care costs. Third, the rate of symptomatic VTE for the follow-up period was not available from the MEDENOX trial. The secondary outcome (VTE rate for days 1 to 110) was not valid for the present study, because during the MEDENOX trial, most asymptomatic VTEs were treated, regardless of the randomization group; consequently, their natural history was altered. To obtain the symptomatic VTE rate for the follow-up period, the experts had to answer the question: "What was the likelihood of the MEDENOX patients becoming symptomatic within three months of discharge, assuming that those patients were discharged home without treatment?"

Model assumptions and structure

In the model, six assumptions were made:

1. Only symptomatic VTEs would be treated and incur health care costs. 


\section{TABLE 1}

Probabilities applied in the decision tree model for the economic evaluation of the Prophylaxis in Medical Patients with Enoxaparin (MEDENOX) trial

\begin{tabular}{|c|c|c|c|c|}
\hline \multirow[b]{2}{*}{ Outcome } & \multicolumn{2}{|c|}{ Probability at discharge (\%) } & \multicolumn{2}{|c|}{ Probability at three months after discharge (\%) } \\
\hline & Enoxaparin & Placebo & Enoxaparin & Placebo \\
\hline Venous thromboembolism & 5.5 & 14.9 & $\mathrm{~N} / \mathrm{A}$ & $\mathrm{N} / \mathrm{A}$ \\
\hline No venous thromboembolism & 94.5 & 85.1 & $\mathrm{~N} / \mathrm{A}$ & $\mathrm{N} / \mathrm{A}$ \\
\hline Pulmonary embolism with or without DVT & 0.0 & 1.0 & $\mathrm{~N} / \mathrm{A}$ & $\mathrm{N} / \mathrm{A}$ \\
\hline DVT alone & 5.5 & 13.9 & $\mathrm{~N} / \mathrm{A}$ & $\mathrm{N} / \mathrm{A}$ \\
\hline Proximal DVT & 1.7 & 4.9 & $\mathrm{~N} / \mathrm{A}$ & $\mathrm{N} / \mathrm{A}$ \\
\hline Distal DVT & 3.8 & 9.4 & $\mathrm{~N} / \mathrm{A}$ & $\mathrm{N} / \mathrm{A}$ \\
\hline \multicolumn{5}{|l|}{ Estimated symptomatic DVT } \\
\hline Symptomatic proximal DVT & $\mathrm{N} / \mathrm{A}$ & $\mathrm{N} / \mathrm{A}$ & 35 & 35 \\
\hline Symptomatic distal DVT & $\mathrm{N} / \mathrm{A}$ & $\mathrm{N} / \mathrm{A}$ & 5 & 5 \\
\hline
\end{tabular}

DVT Deep vein thrombosis; N/A Not applicable

2. All PEs reported as the primary outcome were assumed to be symptomatic and were treated in hospital.

3. All asymptomatic DVT patients were assumed to be discharged with no treatment until they became symptomatic.

4. Once a symptomatic VTE was treated, there would be no recurrence within three months.

5. Patients identified without VTE at discharge were assumed to remain incident-free for three months.

6. For patients who received treatment for PE and DVT at the same time, the model only calculated the cost of treatment for PE to avoid double counting.

Figure 1 illustrates the decision tree structure using DATA 3.5 (Treeage Software Inc, USA) (20). The tree followed the patients along the clinical path of the MEDENOX trial proceeding from left to right. At the beginning of the tree, the decision was made on admission to assign patients randomly to two study arms: $40 \mathrm{mg}$ enoxaparin or placebo. The cost of the prophylactic drug was assigned to the enoxaparin arm. The tree then branched out into three subgroups, with each arm based on the stratified primary outcomes: VTE versus no VTE; PE plus DVT versus DVT alone; and proximal DVT versus distal DVT. Treatment cost was assigned to patients with symptomatic PE. After discharge, the tree was further divided into symptomatic DVT and asymptomatic DVT in each arm. During this period, some patients with asymptomatic DVT may have developed DVT symptoms, been diagnosed, been treated and incurred costs. Others may have remained asymptomatic without treatment or cost consequences.

\section{Probability input}

Table 1 shows the probability input of the model. All clinical VTE rates before discharge were derived from the primary outcome of the MEDENOX trial, in which the total
VTE rate was $5.5 \%$ in the enoxaparin group and $14.5 \%$ in the placebo group. No PE occurred in the enoxaparin group; the symptomatic VTE (PE and PE plus DVT) rate was $1.0 \%$ in the placebo group. The proximal DVT rate was $1.7 \%$ and $4.9 \%$ in the enoxaparin and placebo groups, respectively. The rate of distal DVT was $3.8 \%$ in the enoxaparin group and $9.4 \%$ in the placebo group. For the follow-up period, the symptomatic DVT rate was based on the expert panel's estimation. On average, the estimated symptomatic DVT rate for the follow-up period was 35\% for proximal DVT and 5\% for distal DVT. These estimations were applied to both study arms in the model.

\section{Resource use and cost input}

Cost is the product of resource use and unit cost of each corresponding resource. To measure resource use for VTE management, the model defined the VTE treatment protocol based on the experts' opinions. Data for the corresponding unit costs were derived from various sources. The cost of the prophylaxis drug was based on the manufacturer's wholesale price in Canada. Hospital ward costs were derived from a Modular Case Costing System developed by the CADENCE Research Group, Hamilton Health Sciences General Site (Hamilton, Ontario) (21). Inpatient drug costs were derived from the hospital pharmacy. Outpatient drug costs (enoxaparin and warfarin) were based on a survey of local pharmacies, including dispensing fees. The costs of physicians, diagnostic tests and laboratory tests were based on the 2000 Ontario Health Insurance Plan Schedule of Benefits (22). The Ontario Health Sector Consumer Price Index (23) was used when needed. All costs are reported in year 2000 Canadian dollars.

\section{Cost effectiveness analysis}

Consistent with current guidelines on economic evaluation $(24,25)$, the analysis was performed from a third party payer's perspective. Although a societal perspective is recommended, the third party payer's perspective is also recognized and adopted in many studies (26-28). In the present study, 
because prophylaxis took place in the hospital and the goal was to assess the cost effectiveness of prophylaxis versus placebo in hospitalized acute patients, the third party payers' perspective was thought to be more appropriate.

The time horizon for the study included a seven-day hospitalization period with prophylaxis and a three-month follow-up period. The incremental cost effectiveness ratio was calculated between the two arms (ratio of the difference in expected costs and the difference in expected outcomes).

A number of sensitivity analyses were conducted to examine how robust the analysis was to alternative modelling structure and key variables. In the scenario analysis, the structure was altered from the tertiary hospital setting to the community setting, holding other variables constant. In a one-way sensitivity analysis, 11 variables were tested to account for uncertainties in estimated probabilities and variations in diagnostic resource use.

\section{RESULTS}

Unit costs and resource use

Cost of prophylaxis: Cost estimation for enoxaparin was based on seven-day use - the average length of stay (LOS) reported by the MEDENOX trial. No extra laboratory or nursing time was included in the cost of prophylaxis for three reasons. First, enoxaparin itself does not require laboratory monitoring. Second, because prophylaxis took place during hospitalization, baseline tests determining the complete blood count, activated partial thromboplastin time, prothrombin time and international normalized ratio (INR) were considered to be routine laboratory tests for inpatients. Third, because enoxaparin $40 \mathrm{mg}$ comes in a prefilled syringe, it took less than $1 \mathrm{~min}$ of nurse time to administer the drug. Thus, the total cost of seven days of prophylaxis using enoxaparin $40 \mathrm{mg}$ once daily was $\$ 56 /$ patient at $\$ 8 /$ day. Cost of VTE management: Table 2 shows the estimated VTE management cost per patient. Clinical VTE management included the management of PE and DVT (proximal DVT and distal DVT). Detailed resource use for the management of VTE was based on expert recommendations, which consisted of four major components: ward LOS, the drug, the investigation and physician services. The average unit cost was then added to the corresponding resource component.

Ward cost: All inpatients were assumed to have stayed in a general ward. Of all PE patients, $30 \%$ of them would have an average LOS of 2.5 days; $70 \%$ of the PE patients would have an average LOS of 6.5 days. The average ward cost per patient with PE was $\$ 2,535$. The average ward costs for patients with DVT was $\$ 1,196 /$ patient, with an estimated LOS of 2.5 days.

Investigation cost: The investigations included diagnotic and laboratory tests. On average, patients with PE required two ventilation-perfusion lung scans, and at least one electrocardiogram, chest $\mathrm{x}$-ray, venogram and bilateral ultrasound. Among all patients with PE, 20\% needed a computed tomography scan, and $25 \%$ had an additional $x$-ray. It was estimated that venography was performed in $20 \%$ of patients with distal DVT and 30\% of patients with proxi-

\section{TABLE 2 \\ Cost of VTE management ${ }^{*}$ as determined in the economic evaluation of the Prophylaxis in Medical Patients with Enoxaparin (MEDENOX) trial}

\begin{tabular}{|c|c|c|c|}
\hline & \multicolumn{3}{|c|}{ Cost per patient (\$) } \\
\hline & $\begin{array}{l}\text { Pulmonary } \\
\text { embolism }\end{array}$ & $\begin{array}{l}\text { Proximal } \\
\text { DVT }\end{array}$ & $\begin{array}{l}\text { Distal } \\
\text { DVT }\end{array}$ \\
\hline \multicolumn{4}{|l|}{ Inpatient VTE treatment } \\
\hline Ward & 2,535 & 1,196 & 1,196 \\
\hline Investigation & 913 & 488 & 475 \\
\hline Drug (treatment) & 64 & 30 & 30 \\
\hline Physician and nurse services & 243 & 194 & 194 \\
\hline Total treatment cost for inpatient & 3,755 & 1,908 & 1,895 \\
\hline \multicolumn{4}{|l|}{ Outpatient VTE treatment } \\
\hline Investigation & $\mathrm{N} / \mathrm{A}$ & 458 & 445 \\
\hline Drug (treatment) & $\mathrm{N} / \mathrm{A}$ & 98 & 98 \\
\hline Physician and nurse services & $\mathrm{N} / \mathrm{A}$ & 175 & 175 \\
\hline Total treatment cost for outpatient & $\mathrm{N} / \mathrm{A}$ & 731 & 717 \\
\hline Long term therapy & 204 & 204 & 116 \\
\hline
\end{tabular}

${ }^{*}$ Each cost component is calculated based on the resource consumption in venous thromboembolism (VTE) management as suggested by the experts (see text for details). DVT Deep vein thrombosis; N/A Not applicable

mal DVT to confirm the diagnosis. All inpatients required daily analyses of the complete blood count, prothrombin time, and INR and activated partial thromboplastin time while in hospital. Thus, the average inpatient investigation cost per patient was $\$ 913$ for patients with PE, and $\$ 488$ and $\$ 475$ for patients with proximal and distal DVT, respectively. The average outpatient investigation costs were $\$ 458$ and $\$ 445 /$ patient for patients with proximal and distal DVT, respectively.

Drug cost: Inpatient medication for patients with VTE was started with an intravenous heparin bolus followed by fractionated heparin based on hospital heparin protocol. The ratio of standard heparin to LMWH use while in hospital was 50\%:50\%. Warfarin $10 \mathrm{mg}$ was started on the same day. The average inpatient drug costs were $\$ 64$ for patients with PE, and $\$ 30$ for patients with proximal and distal DVT. For outpatients, LMWH was prescribed based on body weight for an average of five days at an estimated cost of \$98/patient. All patients received warfarin $5 \mathrm{mg}$ daily as long term therapy after the initial treatment. The average cost of long term therapy for PE and proximal DVT was \$204/patient (for a minimum of six months of warfarin therapy and regular INR tests), and was $\$ 116 /$ patient for distal DVT (for a minimum of three months of warfarin therapy and INR tests).

Physician and nurse services cost: During the course of VTE treatment, at least two specialist visits were required for all patients with symptomatic VTE. Inpatients had a daily ward visit by a physician. The average inpatient physician cost was $\$ 243 /$ patient with PE, and \$194/patient with proximal DVT and distal DVT. Outpatients required an additional nurse visit for self-injection instruction. The average outpatient physician and nurse cost was $\$ 175 /$ patient. 
TABLE 3

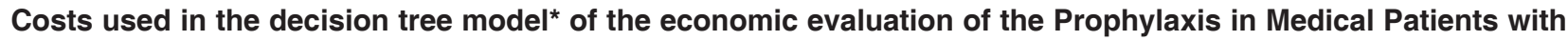
Enoxaparin (MEDENOX) trial

\begin{tabular}{|c|c|c|c|c|c|c|}
\hline & \multicolumn{3}{|c|}{ Prophylaxis (\$) } & \multicolumn{3}{|c|}{ Placebo (\$) } \\
\hline & $\begin{array}{l}\text { Pulmonary } \\
\text { embolism }\end{array}$ & $\begin{array}{l}\text { Proximal deep } \\
\text { vein thrombosis }\end{array}$ & $\begin{array}{c}\text { Distal deep } \\
\text { vein thrombosis }\end{array}$ & $\begin{array}{l}\text { Pulmonary } \\
\text { embolism }\end{array}$ & $\begin{array}{l}\text { Proximal deep } \\
\text { vein thrombosis }\end{array}$ & $\begin{array}{c}\text { Distal deep } \\
\text { vein thrombosis }\end{array}$ \\
\hline \multicolumn{7}{|l|}{ Tertiary setting } \\
\hline Enoxaparin $40 \mathrm{mg}$ once daily ( 7 days) & 56 & 56 & 56 & 0.00 & 0.00 & 0.00 \\
\hline Inpatient treatment & 3,755 & 191 & 189 & 3,755 & 191 & 189 \\
\hline Outpatient treatment & 0.00 & 658 & 646 & 0.00 & 658 & 646 \\
\hline Long term treatment & 204 & 204 & 116 & 204 & 204 & 116 \\
\hline Total cost per patient & 4,015 & 1,109 & 1,007 & 3,959 & 1,053 & 951 \\
\hline \multicolumn{7}{|l|}{ Community setting } \\
\hline Enoxaparin $40 \mathrm{mg}$ once daily ( 7 days) & 56 & 56 & 56 & 0.00 & 0.00 & 0.00 \\
\hline Inpatient treatment & 3,755 & 954 & 947 & 3,755 & 954 & 947 \\
\hline Outpatient treatment & 0.00 & 365 & 359 & 0.00 & 365 & 359 \\
\hline Long term treatment & 204 & 204 & 116 & 204 & 204 & 116 \\
\hline Total cost per patient & 4,015 & 1,579 & 1,478 & 3,959 & 1,523 & 1,422 \\
\hline
\end{tabular}

${ }^{*}$ The total expected cost for each arm is calculated as the probability-weighted sum of these costs

TABLE 4

Incremental cost effectiveness ratios as determined in the economic evaluation of the Prophylaxis in Medical Patients with Enoxaparin (MEDENOX) trial

\begin{tabular}{|c|c|c|c|c|c|c|}
\hline Setting & Strategy & $\begin{array}{l}\text { Rate of symptomatic } \\
\text { venous thromboembolism }\end{array}$ & $\begin{array}{c}\text { Cost per } \\
\text { patient (\$) }\end{array}$ & $\begin{array}{c}\text { Cost } \\
\text { increment }\end{array}$ & $\begin{array}{l}\text { Outcome } \\
\text { increment }\end{array}$ & $\begin{array}{l}\text { Incremental cost } \\
\text { effectiveness ratio }\end{array}$ \\
\hline \multirow[t]{2}{*}{ Tertiary } & Placebo & 0.031 & 62 & & & \\
\hline & Enoxaparin & 0.008 & 64 & $\$ 2$ & -0.023 & \$87/VTE avoided \\
\hline \multirow[t]{2}{*}{ Community } & Placebo & 0.031 & 72 & & & \\
\hline & Enoxaparin & 0.008 & 68 & $-\$ 4$ & -0.023 & -\$174/VTE avoided \\
\hline
\end{tabular}

Cost effectiveness of VTE prophylaxis

Tertiary hospitals: The basic case scenario of the cost effectiveness analysis was in a tertiary hospital setting, where $10 \%$ of patients with symptomatic DVT were treated as inpatients and $90 \%$ as outpatients. Based on this ratio, the estimated treatment cost was calculated and is shown in Table 3. For $\mathrm{PE}$, the average treatment cost was $\$ 3,959 /$ patient. Inpatient average treatment costs were $\$ 191$ for patients with proximal DVT and $\$ 189$ for patients with distal DVT. For outpatients, the average treatment cost was $\$ 658$ and $\$ 646$ for patients with proximal and distal DVT, respectively. The cost of long term therapy for PE and proximal DVT was \$204; for distal DVT, it was $\$ 116$. The cost of the prophylactic drug was $\$ 56 /$ patient in the enoxaparin group.

Table 4 illustrates the cost effectiveness of the two strategies in terms of the expected symptomatic VTE rate and the total expected cost per patient in the two arms. The expected symptomatic VTE rate was $0.8 \%$ in the enoxaparin group and $3.1 \%$ in the placebo group. The total expected cost per patient was $\$ 64$ in the enoxaparin group and $\$ 62$ in the placebo group. The incremental cost effectiveness ratio was $\$ 87 /$ VTE avoided, indicating that to prevent one addi- tional symptomatic VTE, an additional cost of $\$ 87$ is required per patient.

Community hospitals: The alternative scenario was set in a community hospital, where the inpatient to outpatient ratio of DVT management was 50\%:50\%. Based on this ratio, the estimated inpatient treatment costs for proximal and distal DVT were $\$ 954$ and $\$ 947 /$ patient, respectively, in both study arms. The inpatient treatment cost for PE was $\$ 3,755 /$ patient. The outpatient treatment cost was $\$ 365$ and \$359 for proximal DVT and distal DVT, respectively. The average long term therapy cost was $\$ 204$ for PE and proximal DVT, and $\$ 116$ for distal DVT. The cost of the prophylactic drug was $\$ 56 /$ patient in the enoxaparin group.

The expected VTE rates were $0.8 \%$ and $3.1 \%$ for the enoxaparin and placebo groups, respectively, as in the basic scenario. The total expected cost was $\$ 68 /$ patient in the enoxaparin group and $\$ 72 /$ patient in the placebo group. Thromboprophylaxis with enoxaparin $40 \mathrm{mg}$ once daily in community setting was a cost saving strategy, because it not only reduced the symptomatic VTE rate, but also reduced the cost (Table 4). 


\section{Sensitivity analysis}

The result was sensitive to the scenario sensitivity analysis, because the structure was altered from a tertiary setting to a community setting. The main difference between the two settings was the inpatient to outpatient VTE treatment ratio. Because the cost of inpatient treatment was more expensive than outpatient treatment, given the same expected outcome rates in both settings, a higher inpatient ratio would imply higher treatment costs. Thus, in the community setting, the cost of the prophylactic drug may be more than offset by the cost saved in treating fewer symptomatic VTEs, if thromboprophylaxis is implemented.

In a one-way sensitivity analysis, variables were altered one at a time within each setting, holding other variables constant. Among these variables, four were estimated symptomatic VTE rates for the follow-up period (proximal and distal DVT in two arms), and seven were major diagnostic test variables (venography for PE, proximal DVT and distal DVT; ultrasound for PE and DVT; $x$-ray; and lung scan).

In both settings, the result was not affected when estimated proximal and distal DVT rates were altered in the enoxaparin treatment arm of the study within the range suggested by the experts. However, the result was sensitive to the estimated DVT rate in the placebo group. In the tertiary setting, the result became cost saving when the estimated rates of proximal and distal DVT in the placebo group were set in the upper range $40 \%$ and $8 \%$, respectively, compared with the base rate of $35 \%$ and $5 \%$, respectively). When the proximal and distal DVT rates were tested at a rate below the base rate (35\% and 5\%, respectively), the incremental cost effectiveness ratio increased from $\$ 87 /$ VTE avoided to up to $\$ 187$ and $\$ 277 /$ VTE avoided for proximal and distal DVT, respectively. In the community setting, when the estimated rate of distal DVT was altered from a $5 \%$ base rate to the lowest range $(0 \%)$, the result was no longer cost saving, but was still cost effective, with an incremental cost of \$119/VTE avoided.

In the tertiary setting, the result did not change with respect to all seven diagnostic test variables as the model reduced the number of diagnostic tests from the expertsuggested number to zero tests. In the community setting, the result was sensitive to two of five variables, namely, ultrasound for DVT and lung scan. As the number of these tests was altered from the experts' suggested level (two for lung scan and three for ultrasound) to zero, the result was no longer cost saving, but was still cost effective, with an incremental cost of $\$ 36 / \mathrm{VTE}$ avoided for both tests.

\section{DISCUSSION}

For a number of reasons, the assumptions used in the development of the model were very conservative, favouring the placebo group. First, the model assumed that patients in both the enoxaparin and the placebo groups had the same likelihood of becoming symptomatic within three months after prophylaxis. However, the MEDENOX trial found that patients in the $40 \mathrm{mg}$ enoxaparin treatment group had smaller clots; thus, these patients were suspected to have a lower risk of becoming symptomatic during the time frame of the study. This finding is supported in the literature; evidence suggests that smaller clots, as a result of prophylaxis, may imply a lower DVT incidence rate, as well as a lower recurrence rate among treated patients $(17,29)$.

Second, the prophylaxis cost used in our model was based on the manufacturer's wholesale price; individual hospitals may be able to negotiate a better price. Also, because this study was conducted from the third party payer's perspective rather than from a societal viewpoint, indirect costs (lost productivity due to VTE, out-of-pocket costs such as cost for transportation, etc) were not included in the calculation. Thus, the overall economic burden of VTE might have been underestimated.

Third, in the tertiary setting, the model calculated resource consumption based on the 10\%:90\% inpatientoutpatient DVT treatment ratio suggested by the expert panel. However, our experts cautioned that 10\%:90\% may be an overestimation because it was based on the practice of well established thrombosis clinics in southern Ontario tertiary hospitals. In the literature, outpatient treatment for proximal DVT has been reported to range from $27 \%$ to $90 \%$ of the total number of patients with proximal DVT (30-34). The $90 \%$ statistic used in our basic scenario is at the high end of the plausible range and thus is extremely conservative. Because the economic implication of outpatient treatment is that outpatient treatment reduces hospital cost, a higher outpatient treatment ratio would have an impact on cost effectiveness in favour of the placebo group. A recently published meta-analysis found that inpatient DVT treatment with LMWH may be associated with less major bleeding compared with outpatient DVT treatment with LMWH due to a lack of rigorous monitoring in outpatients (35). Thus, the economic benefit of outpatient DVT treatment may also be overestimated in this model, because major bleeding would lead to hospital readmission and result in additional consumption of health care resources.

Finally, most clinical trials reported in the literature concerning outpatient DVT treatment have been conducted in tertiary centres, where the community support network has been well established (including availability of general practitioner and pharmacy education, community nurses, patient self-injection and compliance, and community laboratory facilities). Many Canadian community centres lack such support networks. Thus, it is realistic to assume that the outpatient ratio in the community centres was lower than in the tertiary centres. Under this assumption, the model demonstrated that prophylaxis with enoxaparin is a cost effective strategy, because it reduces both clinical outcomes (symptomatic VTE rate) and average total cost (cost of prophylaxis and cost of treating symptomatic DVT).

Our model did not account for bleeding (a commonly used safety end point in most clinical trials with LMWH), because no significant difference in bleeding was reported 
between the two study arms in the MEDENOX study, as well as in other published clinical trials of LMWH $(16,36)$. The model did not attempt to include a recurrence rate, or to capture the cost and consequences of subsequent episodes beyond the three-month time frame or long term side effects of DVT such as chronic venous stasis.

Although standard statistical tests were not conducted in this evaluation due to a lack of individual resources and cost data, sensitivity analyses were performed to account for the uncertainty of the modelling. In the scenario sensitivity analysis, we investigated the impact of different hospital settings on the model result. We define the difference between the two settings based on an inpatient-outpatient ratio of DVT treatment and assumed that the costs of treating symptomatic DVT were same between the two settings. We believe that this assumption is valid, because the patient population in our study requires care in the general ward only, where the main cost components (nurse, drug and physician fees) are the same between the tertiary hospitals and community hospitals from a third party payer's perspective.

\section{REFERENCES}

1. Nurmohamed MT, Rosendaal FR, Buller HR, et al. Low-molecular weight heparin versus standard heparin in general and orthopaedic surgery: a meta-analysis. Lancet 1992;340:152-6.

2. Bergovist D, Benoni G, Bjorgell O, et al. Low-molecular-weight heparin (enoxaparin) as prophylaxis against VTE after total hip replacement. N Engl J Med 1996;335:696-700.

3. Geerts WH, Jay RM, Code KI, et al. A comparison of low-dose heparin with low-molecular-weight heparin as prophylaxis against VTE after major trauma. N Engl J Med 1996;335:701-7.

4. Kakkar VV, Cohen AT, Edmonson RA, et al. Low molecular weight versus standard heparin for prevention of VTE after major abdominal surgery. Lancet 1993;341:259-65.

5. Oster G, Tuden RL, Colditz GA. A cost-effectiveness analysis of prophylaxis against deep-vein thrombosis in major orthopedic surgery. JAMA 1987;257:203-8.

6. Anderson DR, O'Brien BJ, Levine MN, Roberts R, Wells PS, Hirsh J. Efficacy and cost of low-molecular-weight heparin compared with standard heparin for the prevention of deep vein thrombosis after total hip arthroplasty. Ann Intern Med 1993;119:1105-12.

7. Menzin J, Colditz GA, Regan MM, Richner RE, Oster G. Cost-effectiveness of enoxaparin vs low-dose warfarin in the prevention of deep-vein thrombosis after total hip replacement surgery. Arch Intern Med 1995;155:757-64.

8. Hull RD, Raskob GE, Pineo GF, et al. Subcutaneous low-molecularweight heparin vs warfarin for prophylaxis of deep vein thrombosis after hip or knee implantation: An economic perspective. Arch Intern Med 1997;157:298-303.

9. Prevention of venous thromboembolism. International Consensus Statement (guidelines according to scientific evidence). Int Angiol 1997;16:3-38.

10. Clagett GP, Anderson FA Jr, Geerts W, et al. Prevention of venous thromboembolism. Chest 1998;114(Suppl 5):531S-60S.

11. Harenberg J, Roebruck P, Heene DL. Subcutaneous low-molecularweight heparin versus standard heparin and the prevention of thromboembolism in medical patients. Haemostasis 1996;26:127-39.

12. Dahan R, Houlbert D, Caulin C, et al. Prevention of deep vein thrombosis in elderly medical in-patients by a low molecular weight heparin: a randomized double-blind trial. Haemostasis 1986;16:159-64.

13. Bergmann JF, Neuhart E. A multicenter randomized double-blind study of enoxaparin compared with unfractionated heparin in the prevention of venous thromboembolic disease in elderly in-patients bedridden for an acute medical illness. The Enoxaparin in Medicine Study Group. Thromb Haemost 1996;76:529-34.

\section{CONCLUSIONS}

The present economic evaluation of the MEDENOX trial suggests that in a tertiary setting, prophylaxis using enoxaparin $40 \mathrm{mg}$ once daily in medical patients at moderate risk of VTE would reduce thromboembolic risk. The incremental cost effectiveness ratio for enoxaparin compared with placebo is $\$ 87 / \mathrm{VTE}$ avoided. In a community setting, on the other hand, prophylaxis with enoxaparin is cost saving, indicating that prophylaxis not only improved clinical outcomes, but also reduced direct health care costs. Thus, the present findings support the increased use of enoxaparin for thromboprophylaxis in medical patients hospitalized for congestive heart failure, acute infectious diseases and acute respiratory failure.

ACKNOWLEDGEMENTS: The authors would like to thank the panel of experts for their invaluable contributions: Drs Louis Desjardins, Jeffery Ginsberg and Alexander G Turpie. All of these experts gave their permission to be cited in the paper. The present study was supported by an unrestricted grant from Aventis Canada Inc. Aventis Canada Inc did not intervene in the study in any way. None of the authors have any financial interests in Aventis Canada Inc.

14. Lindblad B, Sternby NH, Bergqvist D. Incidence of venous thromboembolism verified by necropsy over 30 years. BMJ 1991;302:709-11.

15. Sandler DA, Martin JF. Autopsy proven pulmonary embolism in hospital patients: are we detecting enough deep vein thrombosis? J R Soc Med 1989;82:203-5.

16. Samama MM, Cohen AT, Darmon JY, et al. A comparison of enoxaparin with placebo for the prevention of venous thromboembolism in acutely ill medical patients. Prophylaxis in Medical Patients with Enoxaparin Study Group. N Engl J Med 1999;341:793-800.

17. Geerts WH, Heit JA, Clagett GP, et al. Prevention of venous thromboembolism. Chest 2001;119(Suppl 1):154S-5S.

18. Pechevis M, Detournay B, Pribil C, Fagnani F, Chalanson G. Economic evaluation of enoxaparin vs placebo for the prevention of venous thromboembolism in acutely ill medical patients. Value Health 2000;3:389-95.

19. Lloyd A, Anderson P, Quinlan DJ, et al. Economic evaluation of prophylaxis of venous thromboembolism in acute medical patients with enoxaparin in the UK. The American Society of Hematology 42nd Annual Meeting. San Francisco, December 1 to 5, 2000. (Abst)

20. DATA 3.5 For HealthCare Users. Williamstown: TreeAge Software Inc, 1999.

21. Smith KM, Lamy A, Arthur HM, Gafni A, Kent R. Outcomes and costs of coronary artery bypass grafting: comparison between octogenarians and septuagenarians at a tertiary care centre. CMAJ 2001;165:759-64.

22. Ontario Ministry of Health and Long-Term Care. Schedule of Benefits Physicians Services under the Health Insurance Act. Toronto: Ontario Ministry of Health and Long-Term Care, 2000.

23. Consumer Price Index, Catalog 62-001-XPB. Ottawa: Statistics Canada, 2001.

24. Canadian Coordinating Office for Health Technology Assessment. Guidelines for Economic Evaluation of Pharmaceuticals in Canada, 2nd edn. Ottawa: Canadian Coordinating Office for Health Technology Assessment, 1997.

25. Canadian Coordinating Office for Health Technology Assessment. A guidance document for the costing process, version 1.0. Ottawa: Canadian Coordinating Office for Health Technology Assessment, 1996.

26. Drummond MF, Davies L. Economic analysis alongside clinical trials. Revisiting the methodological issues. Int J Technol Assess Health Care 1991;7:561-73. 
27. Gold MR, Siegel JE, Russel LB, Weinstein MC. Cost-effectiveness in Health and Medicine. Oxford: Oxford University Press Inc, 1996.

28. Drummond MF, O'Brien B, Stoddart GL, Torrance GW. Methods for the Economic Evaluation of Health Care Programmes, 2nd edn. Oxford: Oxford University Press Inc, 1997.

29. Levine M, Gent M, Hirsh J, et al. A comparison of low-molecularweight heparin administered primarily at home with unfractionated heparin administered in the hospital for proximal deep-vein thrombosis. N Engl J Med 1996;334:677-81.

30. Hull RD, Pineo GF, Raskob GE. The economic impact of treating deep vein thrombosis with low-molecular-weight heparin: outcome of therapy and health economy aspects. Haemostasis 1998;28(Suppl 3):8-16

31. O'Brien B, Levine M, Willan A, et al. Economic evaluation of outpatient treatment with low-molecular-weight heparin for proximal vein thrombosis. Arch Intern Med 1999;159:2298-304.
32. van den Belt AGM, Bossuyt PMM, Prins MH, Gallus AS, Buller HR. Replacing inpatient care by outpatient care in the treatment of deep venous thrombosis - An economic evaluation. Thromb Haemost 1998;79:259-63.

33. Mattiasson I, Berntorp E, Bornhov S, et al. Out-patient treatment of acute deep vein thrombosis. Int Angiol 1998;17:146-50.

34. Buller HR. Outpatient therapy with low-molecular-weight heparins: new perspectives for treatment of deep vein thrombosis. Haemostasis 1998;28(Suppl 3):91-4.

35. Dolovich LR, JS Ginsberg, Douketis JD, et al. A meta-analysis comparing low-molecular-weight heparins with unfractionated heparin in the treatment of venous thromboembolism. Arch Intern Med 2000;160:181-8.

36. Dahan R, Houlbert D, Caulin C, et al. Prevention of deep vein thrombosis in elderly medical in-patients by a low molecular weight heparin: a randomized double-blind trial. Haemostasis 1986;16:159-64. 


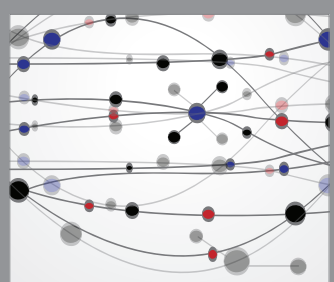

The Scientific World Journal
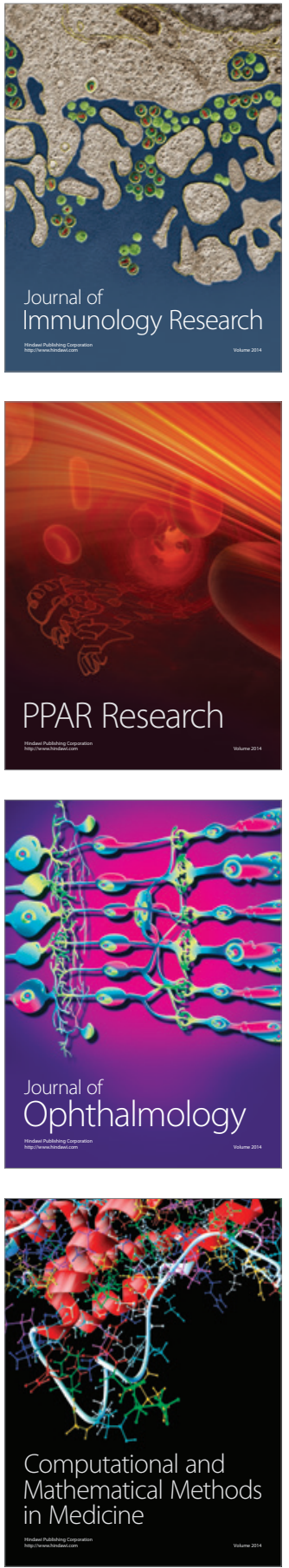

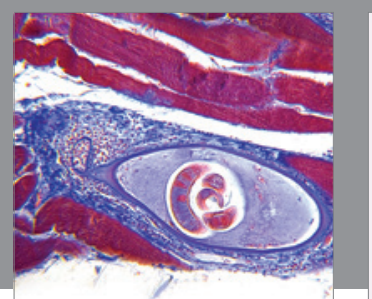

Gastroenterology Research and Practice

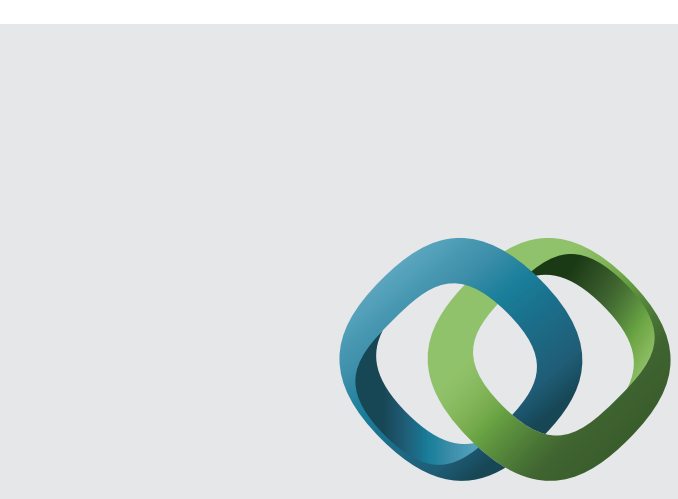

\section{Hindawi}

Submit your manuscripts at

http://www.hindawi.com
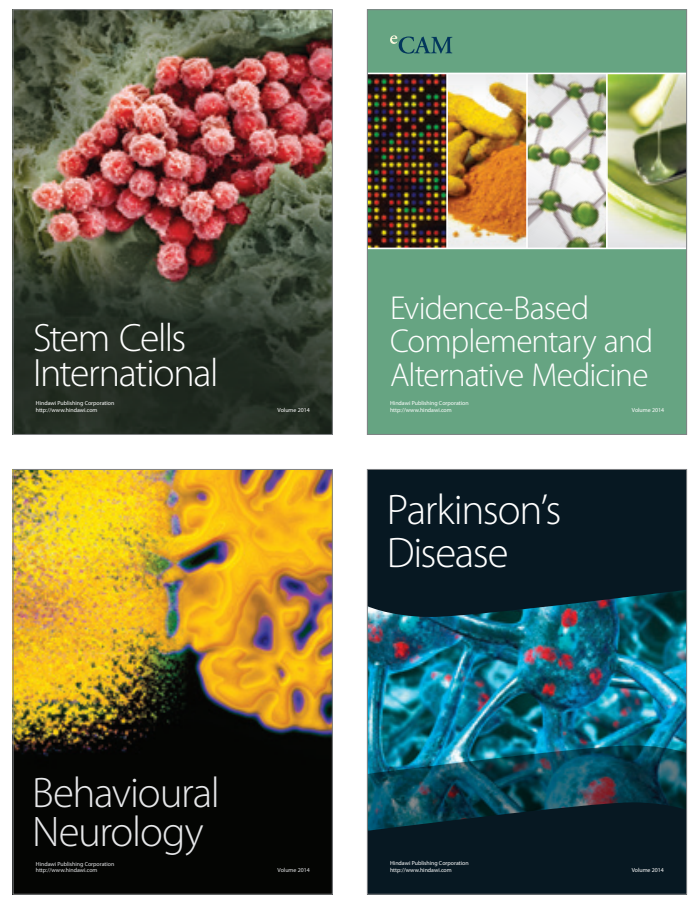
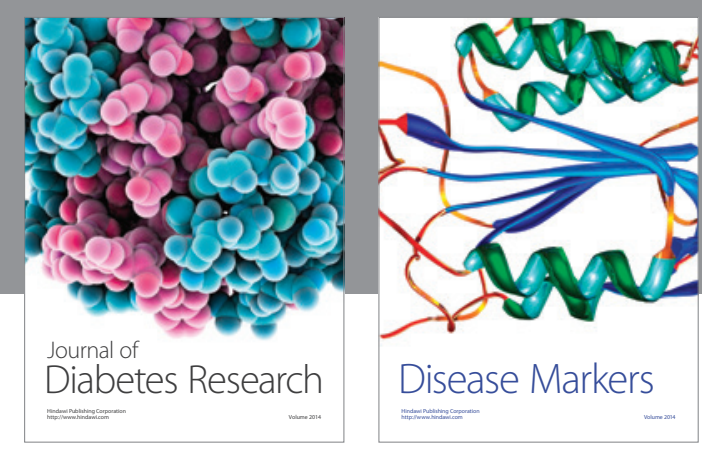

Disease Markers
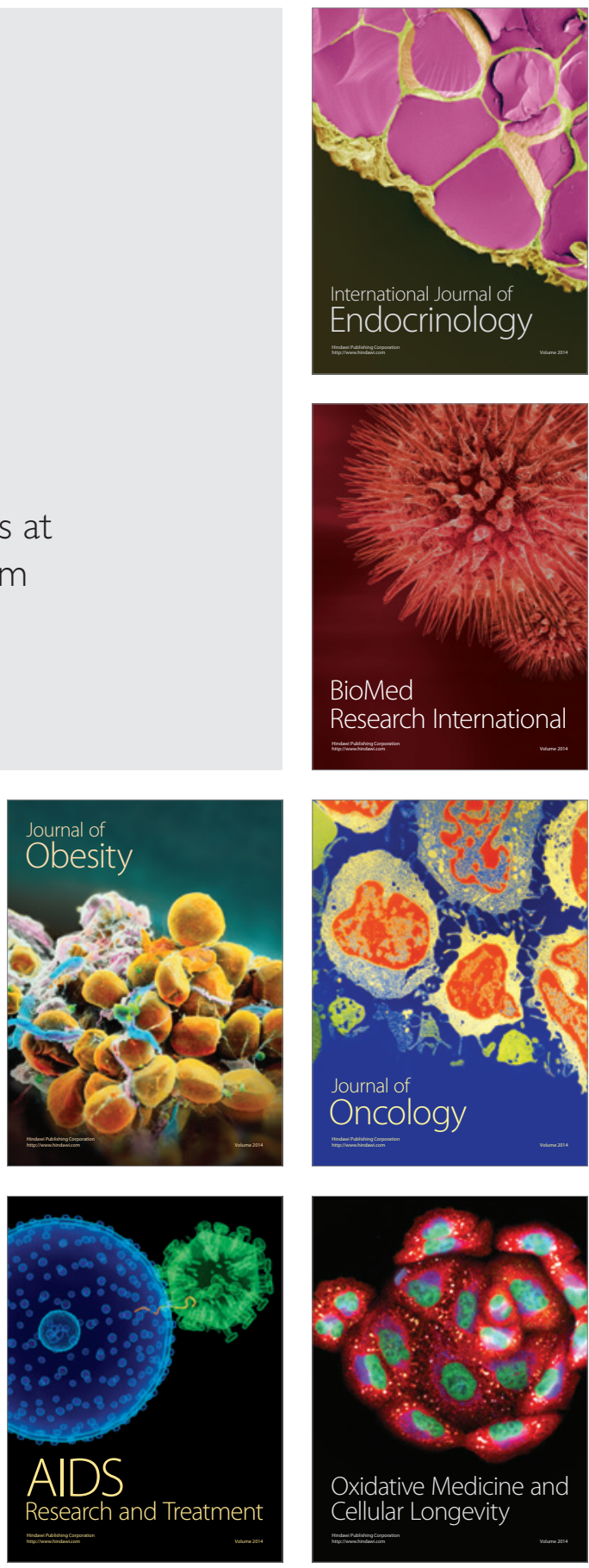